Юшенко Л. П., Цюк О. А.

УДК 632.7/.937:633.15

ОСОБЕННОСТИ БИОЛОГИЧЕСКОЙ ЗАЩИТЫ ПОСЕВОВ КУКУРУЗЫ

ОТ ВРЕДНЫХ ОРГАНИЗМОВ В ЛЕСОСТЕПИ УКРАИНЫ

Л. П. ЮЩЕНКО, кандидат сельскохозяйственных наук, доцент

А. А. ЦЮК, доктор сельскохозяйственных наук, доцент

Национальный университет биоресурсов и природопользования Украины

E-mail: ludmilass@ukr.net

Аннотация. Освещены перспективные направления развития биологической защуиты при производстве экологически чистой продукичи растениеводства. Представлень результаты и использования энтомологического препарата трихограммы на кукурузе. Определено научноорганизачионные мероприятия эффективного использования средств биологической защиты растений. Прослежено повреждаемость початков и стеблей кукурузы стеблевым мотыльком в Лесостепи Украины в 2003-201122. Проведен учет паразитов и хищинков на посевах кукурузы, а также феромониторинг кукурузного мотылька. Определено эффрективность использования энтомофага Trichogramma pintoi nротив Ostrinia nubilalis.

Ключевые слова: биологическая защчита, трихограмма, авиационное внесение, эффективность

Введение. Сельськохозяйственная деятельность - наиболее давняя форма влияния человека на окружающую среду. Синтетические соединения, которые поступают в природу, тоже результат хозяйственной деятельности человека.

В последние десятилетие XX века стало очевидно, что изменнение в биосфере вызваны деятельностью человека, достигли огромных масштабов, что и заставляет говорить о глобальном экологическом кризисе. И хотя среди огромного количества загрязнителей природы на долю пестицидов припадает только 2 \%, масштабное использование их может привести к непредсказуемым последствиям, особенно это касается высокотоксических соединений [1].

Ученые всего мира обеспокоены тотальным использованием пестицидов и последствиями этого, начали поиск путей снижения использования химических препаратов в защите сельскохозяйственных культур от вредных огранизмов. 


\section{Юшенко Л. П., Цюк О. А.}

На сегодняшний день перспективным является предложеная еще в 70-80ых годах интегрированная (комплексная) защита растений, которая основана на четком выполнении агротехнических требований и биологическом методе защиты растений, который базируется на использовании живых организмов, продуктов их жизнедеятельности и биологически активных веществах, то есть зоофагов, энтомопатогенных микроорганизмов, гербифагов, антибиотиков, феромонов, ювеноидов и др., но в отдельных случаях допускается использование даже химических средств локальными способами с минимальной нормой $[1,5]$.

Агроценоз - это сложная биологическая система, имеющая существенные особенности, которые заключаются в наличии большого количества разнообразных экологических ниш, где постоянно присутствуют до 1000 видов членистоногих связаных трофическими цепями [1]. Знание природных механизмов регуляции численности насекомых, служит основой защиты и предполагает избирательное действие на плотность популяции вредителей с максимальным использованием регуляторов созданых природой. Основой построения экологизированной системы защиты является осуществление постоянного мониторинга и прогноза динамики численности вредных и полезных членистоногих определенного агроценоза [3].

Развитие научно обоснованой биологической защиты растений началось в позапрошлом веке. Одни из первых достижений биологического метода связаны с именем профессора Одесского университета И. И. Мечникова (1879), который предложил использовать против вредных насекомых энтомопатогенные микроорганизмы. Но только в 30-е года в ВИЗРе была создана лаборатория микробиологического метода защиты от вредителей и болезней растений во главе с академиком Поспеловым В. П., который в 1932 году представил теоретические основы, которые стали фундаментальными для дальнейшего развития этого направления. Именно академику Поспелову В. П. принадлежит идея массовых выпусков энтомофагов, в часности лабораторной популяции трихограммы [1]. 


\section{Юшенко Л. П., Цюк О. А.}

Не смотря на длительное использование химических технологий защиты растений наблюдается повышение численности и вредоносности многих фитофагов. Так, за последние несколько лет почти в 3-5 раза выросла повреждаемость озимой и другими видами совок на посевах сахарной свеклы, зерновых и овощных культур, а кукурузного мотылька на посевах кукурузы в 4-5 раза.

Особенно значительные повреждения посевов кукурузы наблюдаются кукурузным стеблевым мотыльком (Ostrinia nubilalis Hb.) в условиях Лесостепи Украины (рис. 1).

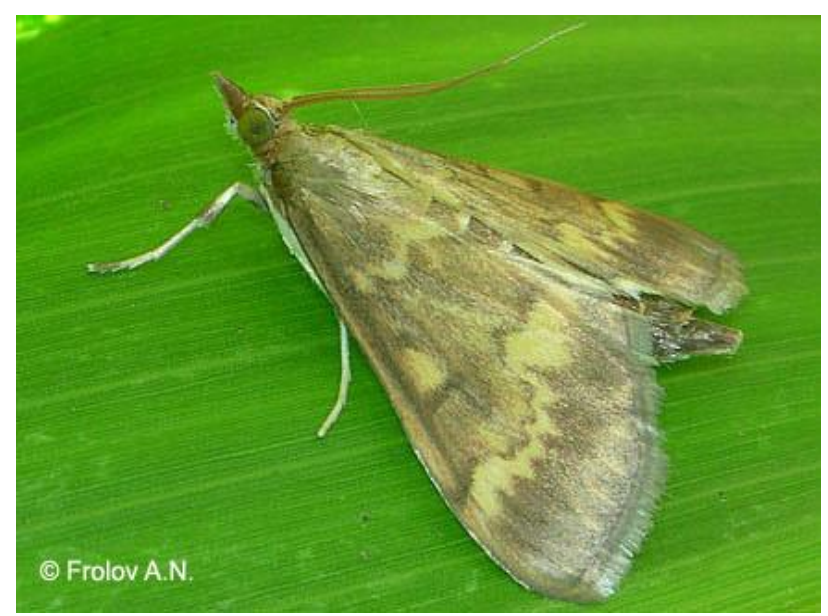

\section{Рисунок 1. Кукурузный стеблевой мотылек}

Вредитель распространен и в Лесостепной, и на севере Степной зон Украины. Повреждает кукурузу, коноплю, подсолнух, просо и другие культуры. Размах крыльев бабочки - 26 - 32 мм. У самки передние крылья желтые или светло-коричневые, с двумя поперечными волновыми линиями, задние - более светлые. Передние крылья самцов светло-коричневые или буросерые с бледно-желтыми полосками, а задние со светлой перевязкой посредине. Гусеница желто-серая с розовым оттенком и темной полоской вдоль спинки, длиной 20 - 25 мм. Зимуют гусеницы в стеблях поврежденных растений. Весной при температуре $15-16^{\circ} \mathrm{C}$ окукливаются. Лет бабочек происходит в июне - июле, и совпадает с началом выброски метелки кукурузы. Яйцекладка начинается через 4-5 суток после вылета бабочек. Самки откладывают яйца 
Юшенко Л. П., Цюк О. А.

черепицеобразно на нижнюю сторону листьев кучками по 15 - 20 шт., в среднем 400 каждая, максимально 1200. Сверху кладка заливается быстрозастывающим раствором и приобретает вид стеариновой капли. Период развития яйца - 3-14 суток. Отрожденные гусеницы на протяжении 1-2 часов находятся открыто на растениях, а затем прячутся в пазухи листьев и метелку и вгрызаются в стебли. До уборки урожая кукурузы они локализуются преимущественно в нижней части стебля, потому значительная их часть остается в пеньках кукурузы после уборки урожая. В первые дни после отрождения гусеницы живут на поверхности растений, потом через пазуху листьев попадают внутрь стебля. Они способны переселяться одного стебля в другой. Температурный оптимум развития гусениц $-23-28^{\circ} \mathrm{C}$, нижний порог относительной влажности - 80\%. На время уборки урожая гусеницы концентрируются преимущественно в нижней части стеблей. В Лесостепной зоне Украины мотылек имеет одну генерацию, а в Степи, где он повреждает главным образом кукурузу, бывает и вторая генерация. Повреждает листья, стебли, метелки, початки, зерно. Гусеницы прогрызают ходы в стеблях, ножках и стержнях початков (рис. 2). Поврежденные стебли от ветра надламываются и опадают, молодые початки и метелки обламываются. В последние годы посевы кукурузы страдают от повреждений стеблевого мотылька почти на 83-87\% [3]. Численность вредителя по годам значительно не отличается и удерживается на уровне 1,5 -1,7 гусениц на растение, повреждение початков составляет 14 20\%, стеблей кукурузы - $21-29 \%$ (рис. 3).

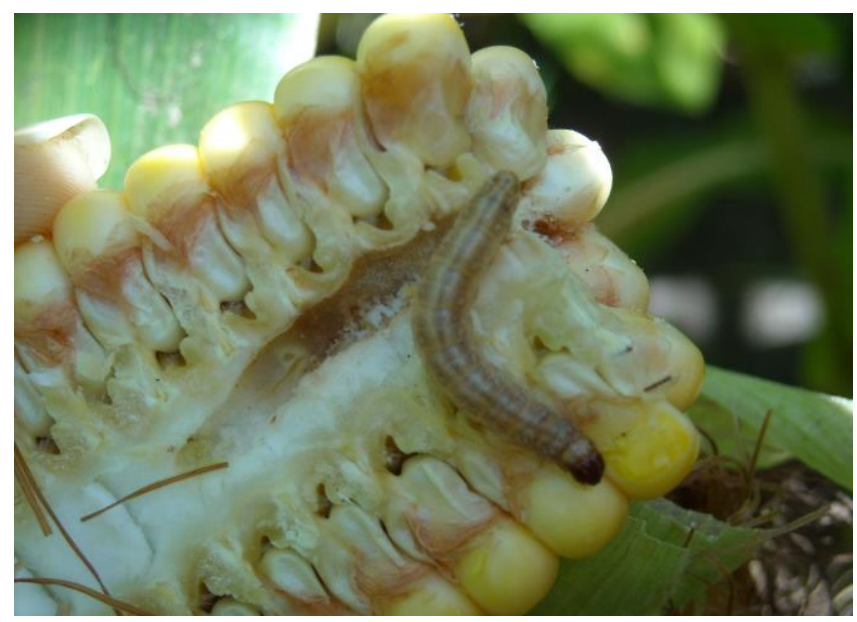

Рисунок 2. Повреждение гусеницей кукурузного мотылька 
Юшенко Л. П., Цюк О. А.

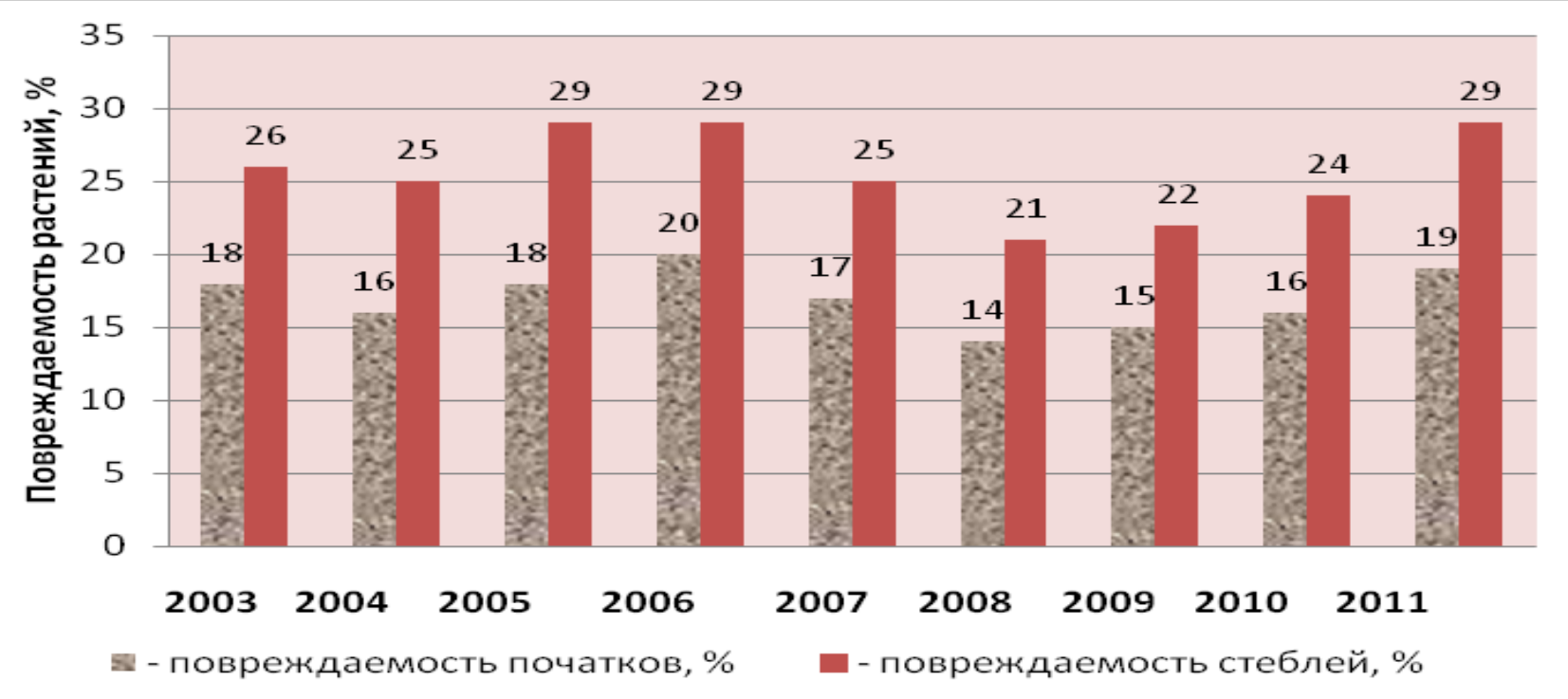

Рис. 3. Повреждаемость початков и стеблей кукурузы кукурузным мотыльком в Лесостепи Украины, ( 2003-2011гг.)

Материалы и методика иследований. В Национальном университете биоресурсов и природопользования Украины функционирует учебная научнопроизводственная лаборатория биологической защиты растений, которая комплексно решает вопрос подготовки высококвалифицированных специалистов, проводит научные исследования и внедряет инновационные технологии в производство. Так, в 2009 - 2011 гг. нами проведена биологическая защита растений кукурузы на зерно против кукурузного стебелькового мотылька энтомологическим препаратом трихограмма в опытном хозяйстве НУБиП Украины «Агрономическая опытная станция» [4]. На протяжении вегетационного периода осуществляли оценку фитосанитарного состояния посевов кукурузы для установления норм, сроков и кратности проведения защитных мероприятий (внесение трихограммы). Внесение энтомологического препарата трихограмма производили с использованием безпилотного сельскохозяйственного самолета R-100.

Результаты и их обсуждение. В среде на каждый организм или группу организмов действуют не только абиотические факторы, но и живые существа, которые являются неотъемлемой частью среды и относятся к категории биотических факторов. Представители каждого вида способны существовать в таком биотическом окружении, где связи с другими организмами обеспечивают 
Юшенко Л. П., Цюк О. А.

им нормальные условия жизни. Основной формой этих связей являются трофические (пищевые) взаимоотношения, на базе которых формируются сложные звенья и цепи питания. Кроме пищевых и группировок растений и животных, возникают пространственные связи. Все это является основой для формирования биотических комплексов, в которых виды объединяются не в любом сочетании, а только при условии приспособления к совместному проживанию. Биотические факторы, влияющие на растительные организмы как первичные продуценты органического вещества могут быть зоогенные и фитогенные.

Практически все классы животных имеют представителей, принадлежащих к типичным фитофагов. По характеру потребления растительной массы для питания фитофаги разделяют на монофаги, олигофаги и полифаг.

Собственно саморегулирующиеся процессы, в основе которых лежит взаимодействие организмов, является, как правило, ответственными за состояние динамического равновесия с внешней средой. В биологической защите растений особенное значение имеют такие формы биотических отношений, как хищничество и паразитизм.

Хищничество - отношения между хищником и жертвой. Хищники - это животные или растения, которые ловят и поедают друг друга как объект питания. По сути, хищниками являются консументы всех порядков - как травоядные, так и те, которые потребляют животную пищу.

Паразитизм - форма биотических связей организмов разных видов, при которой один живет за счет другого, находясь в середине или на поверхности его тела. При этом организм-потребитель использует живого хозяина не только как источник питания, но и как место постоянного или временного проживания. К ним относятся паразитические насекомые (оводы, клещи, комары), паразитические растения, паразитические черви (аскариды).

В течении всего вегетационного периода на посевах кукурузы проводили учет энтомофагов, среди которых были и хищники и паразиты. На обследованных 100 растениях нами обнаружено 102 жука и 37 личинок 
Юшенко Л. П., Цюк О. А.

кокцинеллид, 31 имаго, 20 личинок и 87 яиц златоглазки обыкновенной, а также наличие мух - сирфид.

Кроме кукурузного мотылька посевы кукурузы повреждались и другими вредителями. Особенно высокой численностью отмечалась тля. Из 100 проанализированных растений на 65 зафиксированы колонии тли, которые повреждали листья, стебли, метелки, початки. Встречался трипс - 101 экз./100 растениях, блошки, а также совки.

Проведен феромониторинг кукурузного мотылька для определения сроков появления имаго, а также динамики лета. Использовали феромонные ловушки, которые устанавливали на посевах кукурузы.

Мониторинг посевов проводили с мая до начала августа 2011 г. Первые одиночные бабочки в условиях хозяйства зафиксированы 17 мая 2011 года. Постепенно численность вредителя возростала и массовый лет прослеживался с конца июня до средины июля (рис. 4).

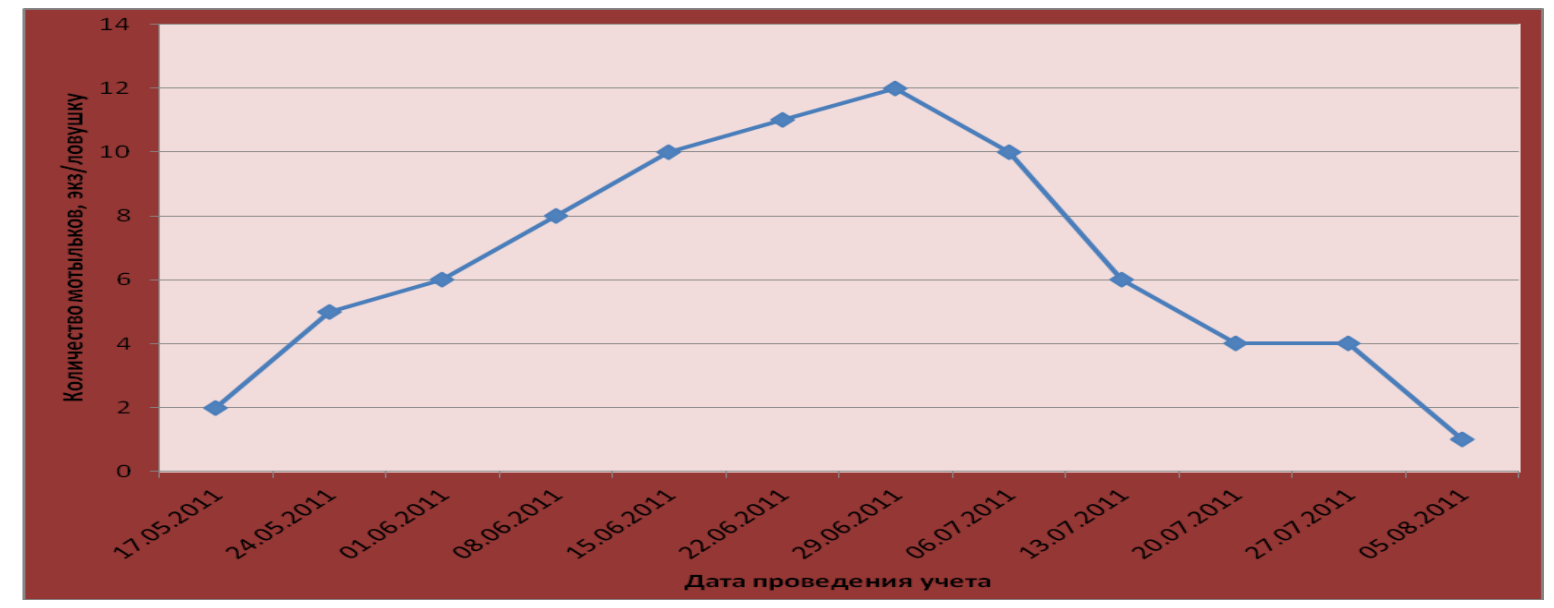

Рис. 4. Динамика лета кукурузного стеблевого мотылька на посевах кукурузы У Лесостепи Украины ( ВП НУБиП Украины «Агрономическая опытная станция", в 2011 г.)

С помощью беспилотного летательного аппарата нами проведено 2 авиационных внесение энтомологического препарата трихограммы, из расчета - 1,25 г/га. Вносили трихограмму первого класса. Trichogramma pintoi Voeg.: заражение трихограммой яиц хозяина - 90\%; отрождение трихограммы - 
Юшенко Л. П., Цюк О. А.

$87,1 \%$, соотношение полов - 1:1,3, плодотворность самок трихограммы - 44,2 яиц/самку, поисковая способность трихограммы - 85,0 \%. Преимущество этой технологии заключается в своевременном и равномерном расселении трихограммы при любом состоянии поверхности поля, в том числе с учетом конфигурации поля и ячеек повышенной численности вредителя.

Для более точного учета эффективности трихограммы сразу после ее выпуска вывешивали фоновые карточки с яйцами зерновой моли, которые заменяли на новые на протяжении месяца с интервалом 5 суток. Зараженность яиц зерновой моли на карточках варьировалась в пределах $52-81 \%$.

Регулярный учет повреждения растений кукурузы мотыльком показал значительные преимущества на участках с внесением трихограммы, где повреждение стеблей составляло - 24\%, а початков - $12 \%$. На контрольном участке, без внесения трихограммы, эти показатели достигали $38 \%$ и $21 \%$ соответственно (рис. 5).

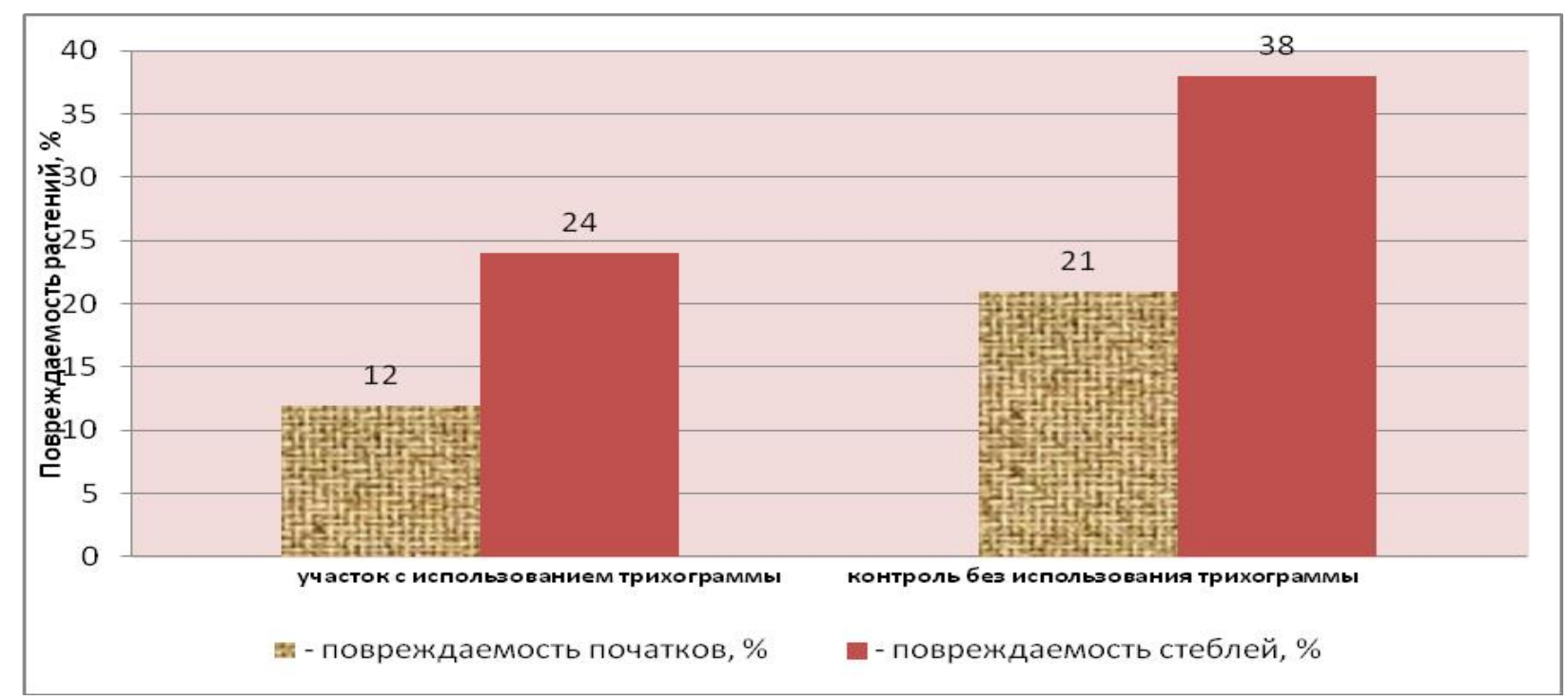

Рисунок 5. Повреждаемость растений кукурузы стеблевым мотыльком в Лесостепи Украины (ВП НУБиП Украины «Агрономическая опытная станция», 2011 г.)

Заключение. Из этого следует, что широкое использование биометода в растениеводческих хозяйства вполне реально и эффективно. В условиях 
Юшенко Л. П., Цюк О. А.

плодородных почв, в благоприятных климатических условиях мы имеем реальные возможности резко увеличить урожаи основных сельскохозяйственных культур [2]. Для этого необходимо объединить усилия специалистов разных отраслей аграрной науки и практики - селекционерам обеспечить создание новых высокопродуктивных сортов повышенной устойчивости к вредителям и болезням; агрономам, разработать и внедрять в практику прогрессивные технологии их регулирование, а защитникам растений обеспечит надежную защиту культур и получение экологически чистой продукции и урожая.

\section{Список литературы}

1. Дядечко Н.П., Падий Н.Н., Шелестова В.С., Барановский М.М. Биологическая защита растений. Белая Церковь, 2001. 311 с.

2. Проект распоряжения Кабинета Министров Украины “Об одобрении Концепции Государственной целевой программы биологизации защиты растений на 2008 - 2012 года" [Электронный ресурс]. Режим доступа : www.minagro.gov.ua.

3. Прогноз фитосанитарного состояния агроценоза Украины. Киев, 2003.2011 Гг.

4. Ющенко Л. П. Эффективность трихограммы против стебельковой бабочки на кукурузе. Вестник НАУ. 2008. № 125. С. 201-205.

5. Ющенко Л. П. Пути экологизации защиты растений от вредных организмов. Харьков, 2007. С. 245-249.

\section{References}

1. Djadechko N. P., Padiy N. N., Schelestova V. S., Baranovskij M. M.(2001). Biologicheskaya zatschita rasteniy. Belaya Tserkva. Ukraine, 311

2. Proekt rasporjyadzenya Kabineta Ministrov Ukraine «Ob odobrenii Konceptciyi Gosudarstvennoy tselevoy programy biologizatciy zatschity rasteniy na 2008-2012 goda» at www.minagro.gov.ua.

3. Prognoz phytosanitarnogo sostoyaniya agrotsenozov of Ukraine (2003). Kiyev, Ukraine,.263.

4. Justschenko L. P. (2008). Effectivnost triphogrammy protiv stebelkovoy babochky na kukuruze. Vestnik NAU, 125, 201-205.

5. Justschenko L. P. (2007). Puti ekologizatsiyi zatschity rasteniy ot vrednih organismov. Kharkov, 245-249. 
ОСОБЛИВОСТІ БІОЛОГІЧНОГО ЗАХИСТУ ПОСІВІВ КУКУРУДЗИ ВІД ШКІДЛИВИХ ОРГАНІЗМІВ В ЛІСОСТЕПУ УКРАЇНИ

\author{
Л. П. Ющенко, О. А. Цюк
}

Анотація. Висвітлені перспективні напрямки розвитку біологічного захисту за виробництва екологічно чистої продукиї рослинництва. Представлені результати використання ентомологічного препарату трихограми на кукурудзі. Визначено науково-організаційні заходи ефективного використання коштів біологічного захисту рослин. Простежено пошкодженість початків $i$ стебел кукурудзи стебловим метеликом в Лісостепу Украйни в 2003-2011 рр. Проведено облік паразитів і хижаків на посівах кукурудзи, а також феромоніторінг кукурудзяного метелика. Визначено ефективність використання ентомофага Trichogramma pintoi проти Ostrinia nubilalis.

Ключові слова: біологічний захист, трихограмма, авіаційне внесення, ефективність

\title{
FEATURES BIOLOGICAL PROTECTION OF MAIZE CROPS FROM PESTS IN THE FOREST-STEPPE UKRAINE
}

\section{Yuschenko, A. Tsyuk}

Annotation. This article is shown perspective direction of development biological plant protection, with produce ecology clean production. The results of using entomofague Trichogramma on the maize are presented.The scientific organization measures of effective using biological means of plant protection are certain. The damageability of corncobs and corn stalks by a stem moth for the period of 2003 through 2011 in the Forest-Steppe of Ukraine was studied. Much attention is given to inventory of parasites and predaceous organisms as well as to pheromonitoring of corn moth. Also it was determined the efficacy in use of the entomophage Trichogramma pintoi against Ostrinia nubilalis.

Key words: biological protection, truchogramma, aircraft making, efficiency 